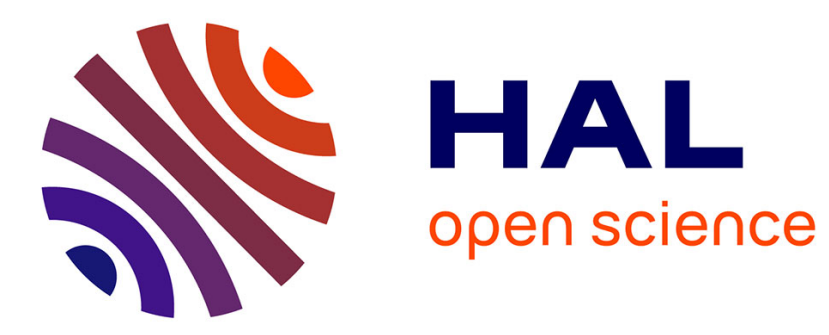

\title{
Some aspects of the compression and collapse behaviour of an unsaturated natural loess
}

José Munoz-Castelblanco, Pierre Delage, Jean-Michel Pereira, Yu-Jun Cui

\section{To cite this version:}

José Munoz-Castelblanco, Pierre Delage, Jean-Michel Pereira, Yu-Jun Cui. Some aspects of the compression and collapse behaviour of an unsaturated natural loess. Géotechnique Letters, 2011, pp.1-6. 10.1680/geolett.11.00003 . hal-00655467

\section{HAL Id: hal-00655467 \\ https://hal.science/hal-00655467}

Submitted on 30 Dec 2011

HAL is a multi-disciplinary open access archive for the deposit and dissemination of scientific research documents, whether they are published or not. The documents may come from teaching and research institutions in France or abroad, or from public or private research centers.
L'archive ouverte pluridisciplinaire HAL, est destinée au dépôt et à la diffusion de documents scientifiques de niveau recherche, publiés ou non, émanant des établissements d'enseignement et de recherche français ou étrangers, des laboratoires publics ou privés. 


\title{
Some aspects of the compression and collapse behaviour of an unsaturated natural loess
}

\author{
J. Muñoz-Castelblanco, P. Delage ${ }^{1}$, J.M. Pereira, Y.J. Cui \\ Ecole des Ponts ParisTech, CERMES/Navier, Université Paris-Est \\ ${ }^{1}$ Corresponding author
}

\begin{abstract}
The compression and collapse behaviour of a natural unsaturated loess from Northern France was investigated by running a series of constant rate of strain oedometric compression tests (together with some step loading tests) while monitoring suction by means of a high capacity tensiometer. The reasonably constant suction measured during constant water compression tests was linked to the collapse of the largest dry pores. A time dependent behaviour was also observed, with different responses obtained at different strain rates. In a standard fashion, collapse tests appeared to bring the representative point from the constant water content curve to the zero suction compression curve, evidencing the existence of a maximum collapse stress. Data were qualitatively interpreted by using the Loading Collapse (LC) yield curve of the Barcelona Basic Model. Changes in the LC curve inclinations could account for the existence of a maximum collapse value.
\end{abstract}

Keywords: natural loess, collapse, unsaturated, suction, loading collapse, time dependent.

\section{Introduction}

Some problems related to the collapsibility of loess deposits in Northern France (Antoine et al. 2003) in areas crossed by the "TGV Nord" high speed train line have been described in Cui et al. (2004). As seen in Figure 1, impressive sinkholes were observed during the construction period when loess layers that were previously protected from rain by an upper superficial illuviated clayey layer were exposed to climatic effects (drying and raining).

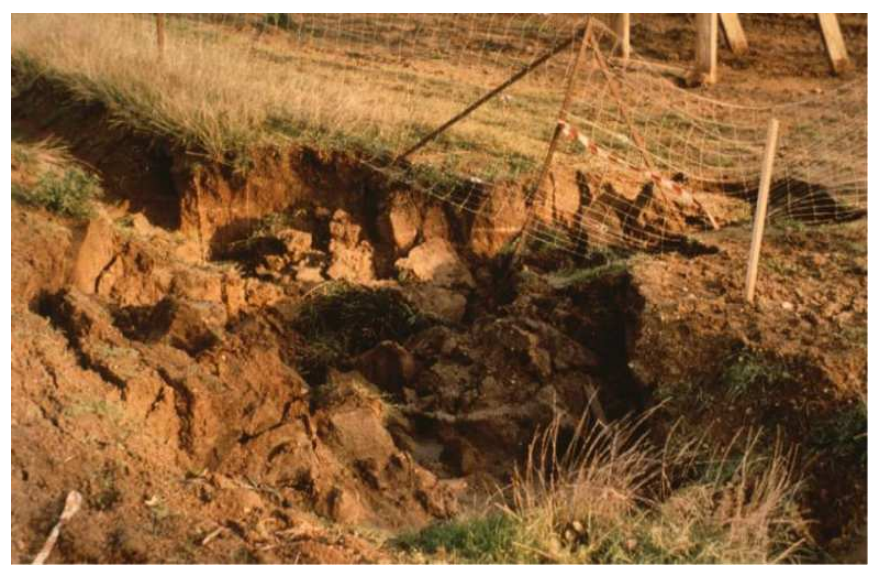

Figure 1. Collapse behaviour in shallow layers of loess directly exposed to climatic actions

Following Jennings and Knight (1957), soil collapse has been investigated either by using the double oedometer technique or by performing soaking tests under constant stress. The 
developments carried out in the past decades in the mechanics of unsaturated soils allow a better understanding of collapse thanks to a relevant theoretical framework (BBM model, LC curve, Alonso et al. 1987, 1990) and to advanced techniques of either controlling (e.g. Maâtouk et al. 1995) or measuring suction (e.g. Jotisankasa et al. 2007) in collapsible samples. To date, these approaches were mainly applied to reconstituted collapsible soils. This work is devoted to the behaviour of a natural aeolian loess, investigated by running constant water content oedometer compression tests with suction measurements. Results were interpreted by using the LC curve concept developed within the BBM model.

\section{Experimental programme}

Tests were performed on good quality samples trimmed from a block that was manually extracted at a depth of $1 \mathrm{~m}$ in October 2007 during a rather cool, dry and sunny autumn. As seen in Table 1, the loess has a 9\% plasticity index and contains $6 \%$ carbonate, a component known to provide inter-particles bonding ("Loess is not just the accumulation of dust", Pécsi 1990). Its water retention properties have been investigated in details in Muñoz-Castelblanco et al. (2011).

Table 1. Geotechnical characteristics of the Bapaume loess

\begin{tabular}{lc}
\hline Sample depth & $1 \mathrm{~m}$ \\
\hline Natural water content $w(\%)$ & 14.4 \\
\hline Natural void ratio $e$ & 0.84 \\
\hline Dry unit mass $\rho_{d}\left(\mathrm{Mg} / \mathrm{m}^{3}\right)$ & 1.45 \\
\hline Natural degree of saturation $S_{r}$ & 0.46 \\
\hline Natural suction $(\mathrm{HTC})(\mathrm{kPa})$ & 40 \\
\hline Clay fraction $(\%<2 \mu \mathrm{m})$ & 16 \\
\hline Silt fraction $(\%)$ & 82 \\
\hline Sand fraction $(\%)$ & 2 \\
\hline Plastic limit $w_{p}$ & 19 \\
\hline Liquid limit $w_{l}$ & 28 \\
\hline Plasticity index $I_{p}$ & 9 \\
\hline Carbonate content $(\%)$ & 6 \\
\hline
\end{tabular}

A series of oedometric compression tests (Table 2) in which, like in Jotisankasa et al. (2007), suction changes were monitored by using an in-house constructed high capacity tensiometer (HCT) located at the base of the sample (Figure 2), was carried out. Oedometer testing was selected in a purpose of simplicity ( $K_{0}$ tests in the triaxial apparatus would have been preferable to get rid of the friction effects along the ring that may overestimate the specimen's mechanical response). Most tests were performed at constant water content starting from the natural unsaturated state ( $w_{i}$ between $14.3 \%$ and $14.9 \%$ ) with initial suctions $s_{i}$ between 38 and $47 \mathrm{kPa}$ (Table 2). Evaporation was prevented by isolating the sample from laboratory atmosphere with a plastic film as indicated in the Figure. In one of the tests, the sample was soaked at very low stress $(1.5 \mathrm{kPa})$ prior to compression by carefully pouring water through the annular gap between the piston and the ring. Water infiltrated the soil through the porous disk and filter paper placed on top of the sample (Figure 2). 
Table 2. Experimental program (SL: Step Loading test, CRS : Constant Rate of Strain test)

\begin{tabular}{|c|c|c|c|c|c|c|c|c|c|}
\hline \multirow[b]{2}{*}{ Test } & \multirow[b]{2}{*}{ Description } & \multicolumn{4}{|c|}{ Initial state } & \multicolumn{4}{|c|}{ Final state } \\
\hline & & $e_{i}$ & $\begin{array}{c}S_{i} \\
(\mathrm{kPa})\end{array}$ & $\begin{array}{c}w_{i} \\
(\%)\end{array}$ & $S_{r i}$ & $e_{f}$ & $\begin{array}{c}s_{f} \\
(\mathrm{kPa})\end{array}$ & $\begin{array}{l}w_{f} \\
(\%)\end{array}$ & $S_{r f}$ \\
\hline SL001 & Natural state & 0.85 & 46.7 & 14.6 & 0.46 & 0.59 & 41.3 & 14.5 & 0.65 \\
\hline SL002 & Saturated & 0.85 & 46.3 & 14.3 & 0.45 & 0.55 & -2.5 & 20.8 & 1.01 \\
\hline SL003 & $\begin{array}{l}\text { Natural state, } \\
\text { collapse/soaking } \\
\text { under } \sigma_{\mathrm{v}}=205 \\
\mathrm{kPa}\end{array}$ & 0.85 & 41.2 & 14.4 & 0.45 & 0.53 & 0.2 & 19.7 & 0.99 \\
\hline SL004 & $\begin{array}{l}\text { Collapse / } \\
\text { soaking under } \sigma_{\mathrm{v}} \\
=19 \mathrm{kPa}\end{array}$ & 0.85 & 47.0 & 14.6 & 0.46 & 0.58 & 3.3 & 22.3 & 1.03 \\
\hline CRS01 & $\begin{array}{l}\text { Natural state } \\
0.003 \% / \mathrm{min}\end{array}$ & 0.84 & 45 & 14.4 & 0.46 & 0.66 & 29 & 14.3 & 0.59 \\
\hline CRS02 & $\begin{array}{l}\text { Natural state } \\
0.010 \% / \mathrm{min}\end{array}$ & 0.84 & 39 & 14.4 & 0.46 & 0.62 & 33 & 14.6 & 0.64 \\
\hline CRS03 & $\begin{array}{l}\text { Natural state } \\
0.059 \% / \mathrm{min}\end{array}$ & 0.84 & 40 & 14.9 & 0.48 & 0.61 & 35 & 14.5 & 0.63 \\
\hline CRS05 & $\begin{array}{l}\text { Saturated, } \\
0.010 \% / \mathrm{min}\end{array}$ & 0.84 & 38 & 14.4 & 0.48 & 0.59 & -2.2 & 22.9 & 1.04 \\
\hline
\end{tabular}

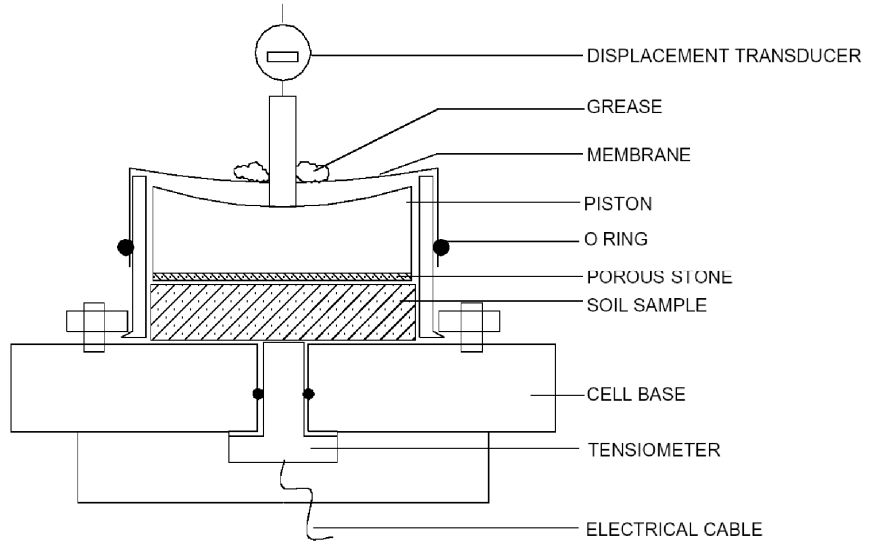

Figure 2. HCT measurement inside an oedometer cell (Delage et al. 2007)

Compression of the soaked sample provided the "saturated" reference compression curve. Constant water content tests were made to compare the unsaturated compression behaviour (with preserved natural structure) with the saturated one, like in the double oedometer test. As noted by Tarantino and De Col (2008), constant rate of strain (CRS) compression tests are preferable when monitoring suction changes. This was done here together with standard $24 \mathrm{~h}$ long step loading tests (with suction and displacement rates finally equal to $2 \mathrm{kPa} / \mathrm{h}$ and $27 \mu \mathrm{m} / \mathrm{h}$ respectively).

\section{Time dependent behaviour}

The response of the CRS tests carried out at rates of $0.003,0.010$ and $0.059 \% / \mathrm{mn}$ are presented in Figure 3 in both linear and semi-log plot of the vertical net stress $\left(\sigma_{v}-u_{a}\right.$, where $u_{a}$ is the air pressure), together with the responses in suction. Given the low values of the 
degree of saturation (Table 1), the air phase is continuous and the pore air pressure is equal to the atmospheric pressure that prevails in the upper porous stone, giving $u_{a}=0$ at all times.
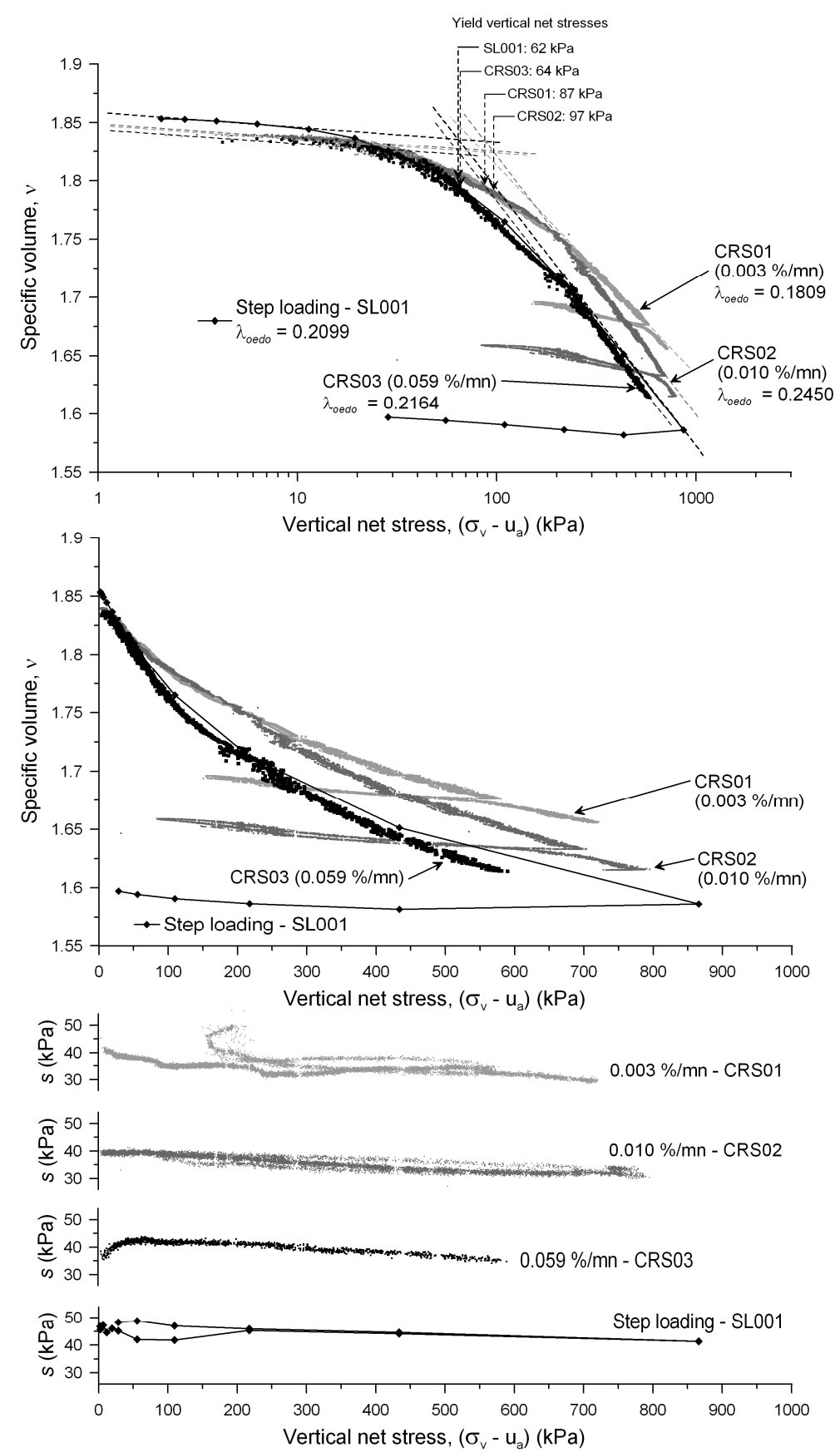

Figure 3. The effect of strain rate in the response at constant water content.

Compared to compacted soils that keep the memory of the compaction stress (Cui and Delage 1996, Maâtouk et al. 1995, Jotisankasa et al. 2007), the response observed here in a natural soil at all rates is not strictly elasto-plastic and exhibit a less apparent yield stress in the semi$\log$ plot. Indeed, yield is not due to any previous maximum supported stress, given the aeolian origin of the soil. As in structured soils, it is linked to a loose structure and to inter-particle bonding. The various available methods of determining gross yield are known to provide different values. In a purpose of simplification, gross yield was determined here at the intersection of two lines fitted on the pseudo-elastic and plastic section of the compression curve respectively. 
Figure 3 shows that the response of the CRS tests is time dependent, in particular in terms of (visco)-plastic compressibility as illustrated by the slope of the curve $\left(\lambda_{\text {oedo }}\right)$ in the post-yield regime, that shows that the unsaturated loess appears to be stiffer at smaller strain rates. The ordering of yield stresses with respect to strain rate is less clear, in particular between tests CRS01 $(0.003 \%, 87 \mathrm{kPa})$ and CRS02 $(0.010 \%, 97 \mathrm{kPa})$, due to the sensitivity of the determined yield with respect to the lines drawn. The distinction with the fastest test CRS03 $(0.059 \%, 64 \mathrm{kPa}$, that corresponds well with the step loading test SL001) is more apparent, with a smaller yield at faster rate. This trend, different from what is observed in saturated fine grained soils and/or sands, should obviously be confirmed by further investigation. The smallest yield stress and highest compressibility of the step loading test could come from the dramatic impact of instantaneous loading on a porous metastable unsaturated structure (step loading is better adapted in saturated samples). The reason why tests SL001 and CRS03 correspond so nicely is not straightforward.

The responses in suction are fairly comparable at 0.003 and $0.010 \% / \mathrm{mn}$ with a progressive decrease from the initial value $(40 \mathrm{kPa})$ to $32 \mathrm{kPa}$. They are fairly reversible at $0.010 \% / \mathrm{mn}$, whereas larger suction variations are observed at $0.003 \% / \mathrm{mn}$ (CRS01, CRS04). At higher rate $(0.059 \% / \mathrm{mn})$ and with the step loading procedure, the responses are different with a rapid initial increase followed by a progressive decrease that ends at a comparable suction value.

\section{Collapse behaviour}

All the initial states of the samples tested in Figure 4 have the same initial void ratio $(0.85)$, showing fairly good homogeneity within the block. Tests include:

- The SL001 step loading test at constant initial water content $(14.6 \%)$ that presents excellent correspondence with test CRS03 $(0.059 \% / \mathrm{mn}, w=14.4 \%)$;

- The SL002 step loading test of a sample previously soaked under $1.5 \mathrm{kPa}$ (no collapse) that presents excellent correspondence with test CRS05 carried out after soaking under $3 \mathrm{kPa}$ (no collapse);

- The SL003 step loading collapse test (soaking at $205 \mathrm{kPa}, 2.3 \%$ collapse) that presents excellent correspondence with test CRS03 before collapse and with tests SL002 and CRS05 after collapse;

- The SL004 step loading test with soaking at $19 \mathrm{kPa}$ (close to the $16 \mathrm{kPa}$ in-situ stress, $3.8 \%$ collapse) that presents excellent correspondence with test CRS03 before collapse and good correspondence with tests SL002 and CRS05 after collapse, confirming the (well known) validity of Jennings and Knight's approach.

The responses in suction are reasonably constant in all tests. As a result, comparable suction decreases occurred during both collapses at 205 and $19 \mathrm{kPa}$. Constant suction during compression was observed by some authors in samples compacted dry of optimum (e.g. Tarantino and De Col 2009) but not in all cases (Jotisankasa et al. 2007).

Various observations can be made from Figure 4:

- There is excellent correspondence between all tests, showing the good quality and homogeneity of the samples tested and of the experimental procedures;

- All rebound curves are comparable, confirming the independence of the BBM $\kappa$ parameter (slope of the curve in the elastic range) with respect to suction, a trend also observed by Jotisankasa et al. 2007 in a artificial collapsible soil;

- Irreversible strain appears to develop from low stress in tests at zero suction (CRS05, SL002), reducing the yield stress to about $3 \mathrm{kPa}$;

- Accordingly, the mutual positions of the constant water content and zero suction curves evidence above $3 \mathrm{kPa}$ the progressive development of collapse (an irreversible 
strain) up to a maximum under $30 \mathrm{kPa}$. Below $30 \mathrm{kPa}$, the unsaturated sample is less compressible than the saturated one (in agreement with the BBM model). Above, it becomes more compressible, as observed by Wheeler and Sivakumar (1995). The constant water content curve progressively joins the zero suction line, with an intersection probably located between 1000 and $2000 \mathrm{kPa}$. The existence of a maximum collapse has been integrated in some constitutive models (e.g. Josa et al. 1992 and Georgiadis et al. 2008);

- The collapse strain at $19 \mathrm{kPa}(3.8 \%)$ is larger than that at $205 \mathrm{kPa}(2.3 \%)$. Indeed, 19 $\mathrm{kPa}$ is located below yielding $(63 \mathrm{kPa})$ whereas a compressive plastic strain of about $10 \%$ developed prior to the plastic collapse strain of $2.3 \%$;

- The changes in collapse with vertical stress are illustrated in Figure 5 that clearly shows the maximum collapse at $30 \mathrm{kPa}$.

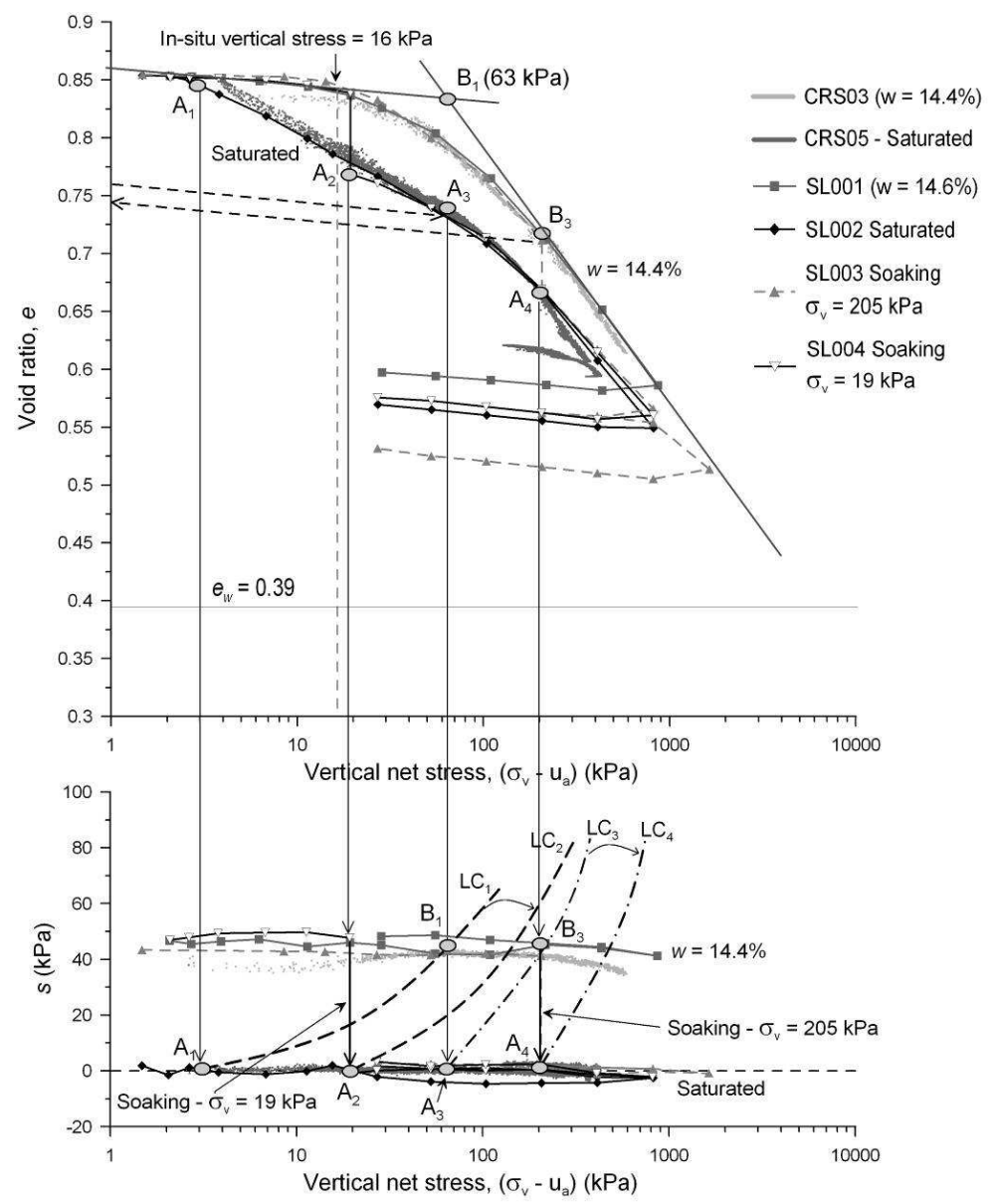

Figure 4. Collapse and compression tests performed

\section{Discussion}

The small suction changes observed during compression can be related to the low saturation state of the samples with degrees of saturation increasing from $47 \%$ to $62 \%$ (Table 2). Based on Laplace's capillary law and under the approximate hypothesis of cylindrical pores, a $40 \mathrm{kPa}$ suction corresponds to a pore diameter of $7.5 \mu \mathrm{m}$, which means that larger pores should be dry. Given that the loess pore size distribution curve (not shown here for brevity, see Munoz-Castelblanco 2011) shows that $6.8 \%$ of the pore volume corresponds to larger inter-grains pores with diameter between 16 and $363 \mu \mathrm{m}$, it is believed that compression occurs by the breakdown of these larger and weaker dry pores with little effect on smaller water saturated pores that govern suction changes (Delage 2009). 
At any stress, collapse brings the representative point from the constant water compression curve down to the "saturated" compression curve. Note however, as shown in Figure 4 (in which both the constant saturated void ratio $-e_{w}=0.39$ ), that collapse is far from erasing all the initially dry porosity.

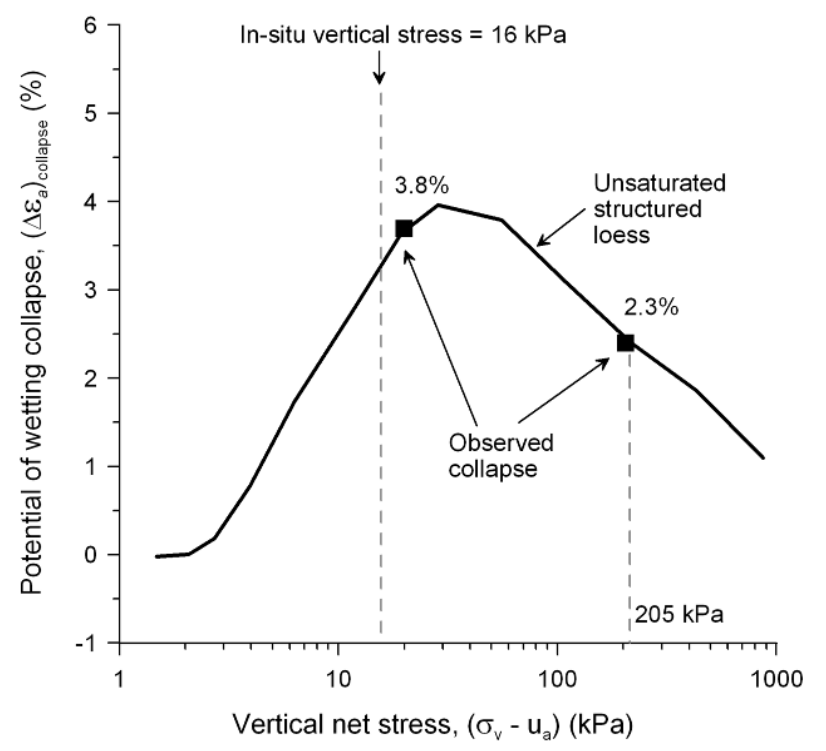

Figure 5. Potential of collapse due to wetting

A qualitative interpretation in terms of change in LC curves with the mobilization of either plastic compression or plastic collapse is proposed in Figure 4 in a $s / \log \left(\sigma_{v}-u_{a}\right)$ plot. The initial $\mathrm{LC}_{1}$ curve represented in the Figure is fully determined by the two yield points at zero suction $\left(\mathrm{A}_{1}\right)$ and at $s \approx 40 \mathrm{kPa}\left(\mathrm{B}_{1}, \sigma_{v}-u_{a}=63 \mathrm{kPa}\right)$. According to the $\mathrm{BBM}$ model, soaking under $19 \mathrm{kPa}$ starts in the elastic region and should first induce a slight elastic swelling (not observed here). As drawn in Figure 4, the vertical soaking path curve then reaches the $\mathrm{LC}_{1}$ curve and plastic collapse corresponds to the moving of point $\mathrm{A}_{1}$ to $\mathrm{A}_{2}$ and of curve $\mathrm{LC}_{1}$ to $\mathrm{LC}_{2}$. Plastic compression at constant water content to $205 \mathrm{kPa}$ moves $\mathrm{LC}_{1}$ to a $\mathrm{LC}_{3}$ curve. $\mathrm{LC}_{3}$ is defined by $\mathrm{B}_{3}\left(s \approx 40 \mathrm{kPa}, \sigma_{v}-u_{a}=205 \mathrm{kPa}\right)$ and $\mathrm{A}_{3}$. The position of $\mathrm{A}_{3}$ is estimated by (virtually) unloading the sample (using the known $\kappa$ parameter), soaking it (with a small rebound defined by an estimated $\kappa_{s}$ parameter) and compressing it elastically up to the yield defined by the intersection with the saturated compression curve $(62 \mathrm{kPa})$. Indeed, the $\mathrm{LC}_{3}$ curve appears to have a smaller inclination than $\mathrm{LC}_{2}$ illustrating a smaller potential collapse (Alonso et al. 1987). $\mathrm{LC}_{3}$ is afterwards moved to $\mathrm{LC}_{4}$ during plastic collapse ( $\mathrm{A}_{3}$ moves to $\mathrm{A}_{4}$ ) with also a smaller estimated inclination.

\section{Conclusions}

Up to date experimental techniques (including collapse tests with suction monitoring) and qualitative constitutive modelling of unsaturated soils have been used in the investigation of the collapse behaviour of a natural aeolian loess from Northern France. Compared to existing data on reconstituted collapsible soils, the following set of conclusions can be drawn for a natural soil:

- Suction measurements showed that constant water content compression tests occurred at a fairly constant suction (even at yielding). This is explained by the compression induced collapse of the largest dry pores of the loess, with little effect on the smaller hydrated pores that control suction changes; 
- Given the aeolian origin of the loess, yield is not related to any previous applied stress but to the bonding due to carbonate re-precipitation between the grains, resulting in less apparent yield values compared to compacted soils;

- The response of the loess to compression is time dependent. Whereas the trend governing the changes in yield stress with strain rate is not very clear and needs further investigation, the plastic compression parameter $\lambda$ appears to be time dependent unlike in saturated fine grained soils that are generally characterised by an isotach-type viscous response;

- A maximum collapse is observed at a vertical net stress of $30 \mathrm{kPa}$;

- The volume change behaviour has been qualitatively interpreted by means of the LC curve concept, the inclination of which varied to account for the existence of a maximum collapse;

- The magnitude of collapse is known to increase with higher suction. This is the case during dry periods, in particular like in Figure 1 when the layer of collapsible loess has been directly exposed to atmosphere and does experience evaporation. As a result, the magnitude of the collapse observed in the photo could be significantly higher than that measured here.

\section{References}

Alonso E., Gens A. and Hight A. (1987). Special problems soils. General Report, Proc. $9^{\text {th }}$ European Conference on Soil Mechanics and Foundation Engineering, Dublin 3, Balkema. 1087-1146.

Alonso E., Gens A. et Josa A. (1990). A constitutive model for partially saturated soils. Géotechnique 40 (3). 405-430.

Antoine P., Catt J. and Sommé J. (2003). The Loess and Coversands of Northern France and Southern England. Journal of Quaternary Science 18. 309-318.

Cui Y.J. and Delage P. (1996). Yielding and plastic behaviour of an unsaturated compacted silt. Geotechnique 46 (2). 291-311.

Cui Y.J., Marcial M., Terpereau J.M., Delage P., Antoine P., Marchadier G. and Ye W.M. (2004). A geological and geotechnical characterisation of the loess of Northern France. A.W. Skempton Memorial Conference, vol. 1. 417-428.

Delage P., Le T.T., Tang A.M., Cui Y.J., Li X.L. 2007. Suction effects in deep Boom clay block samples. Géotechnique 57 (1), 239-244.

Delage P. (2009). Compaction behaviour of clay: discussion. Géotechnique 59 (1). 75-76.

Georgiadis K., Potts D.M. and Zdravkovic L. (2008). An improved constitutive model for unsaturated and saturated soils. In Unsaturated Soils : Advances in Geo-Engineering, Proc. of the $1^{\text {st }}$ European Conference on Unsaturated Soils, Durham, UK, CRC Press. 581-588.

Jennings J.E. and Knight K. (1957). The additional settlement of foundation due to collapse of sandy soils on wetting. Proc. $4^{\text {th }}$ International Conference on Soil Mechanics and Foundation Engineering 1. 316-319.

Josa A., Balmaceda A., Gens A. and Alonso E.E. (1992). An elasto-plastic model for partially saturated soils exhibiting a maximum of collapse. Proceedings of $3 \mathrm{rd}$ International Conference on Computational Plasticity, Barcelona, vol. 1. 815-826.

Jotisankasa A., Ridley A. and Coop A. (2007). Collapse behavior of a compacted silty clay in the suction-monitored oedometer apparatus, Journal of Geotechnical and Geoenvironmental Engineering, ASCE. 867-877.

Maâtouk A., Leroueil S. and La Rochelle P. (1995). Yielding and critical state of a collapsible unsaturated silty soil. Geotechnique 45 (3). 465-477.

Muñoz-Castelblanco J., Pereira J.M., Delage P. and Cui Y.J. (2011). The water retention 
properties of a natural unsaturated loess from Northern France. Géotechnique, accepted for publication.

Muñoz-Castelblanco J. (2011). Comportement hydromécanique d'un lœss naturel non saturé. Thèse de doctorat, Ecole des Ponts ParisTech, Paris, France.

Pécsi M. (1990). Loess is not just the accumulation of dust. Quaternary International 7/8. 121.

Tarantino A. and De Col E. (2008). Compaction behaviour of clay. Géotechnique 58 (3). 199213.

Wheeler S.J. and Sivakumar V. (1995). An elasto-plastic critical framework for unsaturated soil. Géotecnique 45 (1). 35-53. 